\title{
然 \\ INCIDÊNCIA DE LESÕES EM ATLETAS PRATICANTES DO FUTSAL NA CIDADE DE MORRO DO CHAPÉU - PI

\author{
INCIDENCE OF INJURIES IN FUTSAL PRACTICING ATHLETES IN THE CITY OF \\ MORRO DO CHAPÉU - PI
}

Tiago Magalhães Pontes *

\begin{abstract}
Resumo: O presente artigo tem como objetivo geral analisar a ocorrência das lesões em atletas praticantes do Futsal. A metodologia utilizada foi a descritiva, e como instrumento de pesquisa utilizou-se um questionário com perguntas abertas e fechadas. Foram aplicados questionários para 50 atletas com idade entre 15 e 35 anos. Os resultados demonstram que o segmento anatômico mais lesionado foi o tornozelo (22\%). Os jogadores da posição de ala foram os que mais sofreram lesão (40\%). Os jogadores informaram que sofreram mais lesões nos movimentos de chutes (21\%). Os resultados evidenciaram ainda a ocorrência de lesões em quase todos os praticantes de futsal, em que ocorrem mudanças bruscas de direção. Com este estudo, conclui-se que os praticantes do futsal podem ser prejudicados por vários tipos de lesões, mas que as musculoesqueléticas tem uma incidência maior sobre os atletas amadores.
\end{abstract}

Palavras-chave: Lesões Musculoesqueléticas, Atletas, Futsal.

Abstract: This article aims to analyze the occurrence of injuries in athletes practicing Futsal. The methodology used was descriptive and as a research instrument a questionnaire containing open and closed questions was used. Questionnaires were applied to 50 athletes aged between 15 and 35 years. The results show that the anatomical segment most injured was the ankle $(22 \%)$. The players in the ala position are the ones most injured (40\%). The players reported that they suffered more injuries in kicking movements (21\%). The results also showed the occurrence of injuries in almost all futsal practitioners, in which abrupt changes of direction occur. With this study, it can be concluded that futsal practitioners may be harmed by several injuries, but that musculoskeletal ones have a greater incidence on amateur athletes

Keywords: Musculoskeletal injuries, Athletes, Futsal.

\section{Introdução}

O futsal atualmente, além de ser uma das modalidades esportivas mais praticadas no mundo, proporciona uma ótima forma de exercício aeróbico e de desenvolvimento físico, dá agilidade, coordenação e também estimula o trabalho em equipe. No entanto, é um esporte que apresenta uma das maiores incidências de lesões em seus praticantes.

Um esporte que foi adaptado do futebol, mas que utiliza quadras com pisos duros, provoca muito contato físico e exige uma preparação física intensa. Também é um vilão quando

\footnotetext{
* Graduação em Educação Física, pela Universidade Estadual do Piauí-UESPI; Pós-Graduação em Treinamento Desportivo, pela Faculdade INTA, atualmente cursando Mestrado em Educação e também é aluno do curso de Licenciatura em Computação, pela UFPI/UAB. É professor de Educação Física nas redes municipais de Morro do Chapéu-PI e Luzilândia-PI (tiago_pontes44@ @otmail.com).
} 
o assunto é lesão, principalmente nos tornozelos e joelhos. Participam desta modalidade esportiva duas equipes formadas com cinco jogadores cada; a bola é pesada, menor e menos flexível do que a do futebol, por isso esse esporte também é conhecido como o "esporte da bola pesada".

O processo de evolução e profissionalismo que o mundo esportivo vem sofrendo nos últimos anos traz consigo variáveis de intensidade, frequência e duração, gerando um sobrecarregamento nas condições naturais dos atletas praticantes dos esportes de rendimentos. Os treinamentos, que estão cada vez mais intensos e repetitivos, trazem com ele maior incidência de lesões nos membros inferiores, com maior frequência as coxas, joelhos e tornozelos. Dentre as lesões musculares mais comuns destacam-se: isquiotibiais, adutores e quadríceps, tríceps sural, enquanto as lesões articulares mais ocorridas nos praticantes do futsal na cidade de Morro do Chapéu-PI são as entorses de tornozelo e joelhos.

Outros fatores psicológicos que contribuem para o desenvolvimento dessas lesões nos atletas pesquisados estão relacionados a falta de profissionais para orientações técnicas, alimentação não adequada, ao tempo insuficiente de descanso para o corpo, aliado ao consumo de bebidas alcoólicas. Tais fatores justificam o alto índice de jogadores que já sofreram algum tipo de lesão ou encontram-se lesionados no futsal e com graus de complexidade.

O futsal é um esporte que requer muito esforço da musculatura, principalmente dos membros inferiores, que sofrem mais com os deslocamentos intensos, com mudanças bruscas de direções, envolvendo contato com os adversários e com a bola. Esse esporte é praticado em espaços reduzidos e em pisos de superfície rígida, com períodos de sobrecarga de treino e competição e níveis de exigência competitiva elevados, o que acaba propiciando o aparecimento de lesões.

Segundo Sandoval (2005), quando o atleta sofre uma lesão, seja por traumatismo local direto, seja por sobrecarga repetitiva, o padrão neuromuscular se altera profundamente, assim como as suas atividades proprioceptivas, que vão influenciar negativamente em todas as suas valências físicas, reduzindo a performance geral do competidor, principalmente pela presença da dor, edema, isquemias, tensão muscular, contratura muscular reflexa, entre outras causas.

As lesões que ocorrem nesse esporte estão relacionadas a fatores de risco que podem ser classificados em fatores de risco intrínsecos e extrínsecos.

- Fatores intrínsecos são aqueles que pertencem ao próprio indivíduo, como idade, gênero, pouca flexibilidade, déficit de força muscular, lesão prévia, entre outras.

- Fatores extrínsecos são os que não pertencem diretamente ao indivíduo, como tipo de quadra, tênis, carga de treinamento, biomecânica do gesto esportivo, etc.

A lesão resulta da ultrapassagem do limite fisiológico. Muitas vezes ela é incapacitante e determina o afastamento do atleta dos treinamentos e das competições por 
períodos variados para ser tratada de forma correta e coerente. Segundo Andrews, Harrelson e Wilk (2000), a reabilitação é um programa dinâmico de exercícios prescrito para prevenir ou reverter os efeitos da inatividade, e durante ela o atleta recupera toda a funcionalidade que tinha em períodos competitivos. Mas quando se fala em esporte de alto nível, a reabilitação combina exercícios e as modalidades terapêuticas a fim de propiciar o retorno mais rápido possível do atleta, no mesmo nível de condicionamento ou acima do que ele possuía antes da lesão.

É possível perceber que, além de ser um esporte prazeroso e competitivo, também tem um percentual alto de lesões. Dessa forma, o presente trabalho tem como objetivo geral analisar a ocorrência das lesões em atletas praticantes do Futsal; como objetivos específicos, verificar os fatores que contribuem para o aparecimento dessas lesões e identificar os tipos de lesões mais comuns nesses atletas praticantes da modalidade.

A metodologia utilizada foi a descritiva, e como instrumento de pesquisa utilizou-se um questionário de 5 perguntas abertas e fechadas. Foram aplicados questionários para 50 praticantes do esporte pesquisado, com idade entre 15 e 35 anos, que praticam o futsal de forma amadora no município de Morro do Chapéu do Piauí, localizado no norte do estado.

É evidente a importância do estudo das lesões no esporte para que assim possamos desenvolver medidas preventivas e melhoramento dos tratamentos, a fim de que os atletas possam usufruir de uma melhor qualidade de vida e, consequentemente, ter melhor desempenho.

Os resultados demonstram que o segmento anatômico mais lesionado foi o tornozelo, com $22 \%$, seguido do joelho, $18 \%$. Os jogadores da posição de ala foram os que mais sofreram lesão (40\%). Os atletas informaram que sofreram mais lesões em jogos (42\%), e os movimentos mais responsáveis pelas lesões eram os chutes (21\%). Os resultados evidenciaram ainda a ocorrência de lesões em todos os praticantes de futsal, devido à própria característica desse esporte, no qual ocorrem mudanças bruscas de direção e muito contato físico.

\section{Metodologia}

\subsection{As lesões músculoesqueléticas}

Sabe-se que o futsal é um esporte que requer muito treinamento e disciplina. Dessa forma, pode-se observar o que leva os esportistas a desenvolver habilidades que podem favorecer o aparecimento de lesões, com mais incidência nos membros inferiores.

A busca pelo sucesso muitas vezes coloca esses praticantes/atletas em situações de esforços físicos e psíquicos próximo de seus limites, resultando em um alto número de lesões esportivas. Esse limite, quando ultrapassado, faz com que o corpo do atleta seja prejudicado, podendo ocorrer lesões musculares e esqueléticas pelo excesso de carga de esforço físico.

Se analisarmos os atletas profissionais, aqueles que estão sempre em alto nível, pois as competições exigem o máximo dos atletas, eles estão mais propensos ao surgimento de lesões 
dos que os atletas amadores. GAETHER (2012) afirma que "o corpo do atleta de alto nível acaba sendo usado de forma mecânica, e o prazer de jogar muitas vezes é substituído pela necessidade dos resultados impostos pela torcida". Nesse sentido, observa-se que os atletas buscam somente o resultado positivo, mesmo que isso possa submetê-los a uma carga excessiva de esforço físico tanto nos jogos como nos treinamentos. Assim, os atletas amadores também querem buscar a mesma intensidade desses jogadores profissionais, mas por falta de orientação inadequada e preparação física muito abaixo do ideal vêm sofrendo com frequência lesões consideradas graves.

Os treinamentos, que estão cada vez mais intensos e repetitivos, provocam maior incidência de lesões nos membros inferiores e, com maior frequência, nas coxas, joelhos e tornozelos. Entre as lesões musculares mais comuns destacam-se: isquiotibiais, adutores e quadríceps e tríceps sural. Enquanto as lesões articulares mais ocorridas nos praticantes do futsal na cidade de Esperantina são as entorses de tornozelo e joelho.

Segundo o Fisioterapeuta Diego Telarolli, “o índice de lesões mais acentuado se encontra na perna dominante. Além de seu uso preferencial, sofre um maior índice de contato direto e um trabalho unilateral realizado com mais ênfase durante treinamentos, utilizando o membro dominante, principalmente em exaustivos chutes e passes, que podem gerar desgaste às estruturas corporais utilizadas".

Um caso à parte, em se tratando de lesões, são os goleiros. Estes, além da propensão das lesões acima citadas, também costumam apresentar lesões nos membros superiores, principalmente nos dedos, pulso, ombro e cotovelo. As posições dos jogadores de linha não apresentam variações nos tipos de lesões. Devido ao fato de ser um esporte muito dinâmico, há uma constante troca de posicionamento.

A metodologia seguida nos estudos que visam obter informação sobre a incidência de lesões desportivas nos praticantes da modalidade Futsal na cidade de Esperantina-PI é normalmente descritiva e baseia-se na realização de entrevistas aos atletas. Fuller et al. (2005) fazem referência a dois tipos de estudos no âmbito das lesões desportivas: prospectivos (de monitorização ou acompanhamento e registo das ocorrências) e retrospectivos (que apelam à memória dos atletas em termos de ocorrências durante o seu percurso desportivo). Ressaltamos o interesse pelos dois momentos para conhecermos o histórico de lesões em cada jogador/atleta pesquisado.

\subsection{Local da Pesquisa}

A pesquisa foi realizada com 50 atletas amadores praticantes da modalidade futsal que atuam em uma escolinha de futsal do município, com o time feminino Avenida Futsal, que treina durante todo o ano para competições municipais e regionais, e com um grupo de 
jogadores amadores quem treinam três vezes na semana no ginásio poliesportivo da cidade de Morro do Chapéu do PI. Dez dos entrevistados são do sexo feminino e 40 do sexo masculino, na faixa etária de 15 a 35 anos. Os participantes da pesquisa teriam de estar praticando o futsal pelo menos 3 vezes na semana.

\subsection{Procedimentos}

No questionário foram incluídas questões fechadas (o pesquisado escolheu sua resposta a partir de um conjunto de itens) e também questões abertas que dão condição ao pesquisado de discorrer espontaneamente, sem limitações e com linguagem própria. A seleção das questões para o questionário foi baseada na revisão de literatura e nos objetivos geral e específicos desta pesquisa.

A pesquisa começou a ser desenvolvida por meio da observação e conversa com os organizadores responsáveis pelos grupos pesquisados no mês de julho. Então escolhemos as datas do dia 2 de setembro para a coleta de informações na escolinha de futsal, dia 3 de setembro para coletar as informações do grupo feminino de futsal, e o dia 4 de setembro para a entrega e coleta dos questionários no grupo dos amigos que treinam no ginásio da cidade.

Antes da aplicação do questionário, foi solicitada autorização para os responsáveis pelos grupos onde os entrevistados atuam, para conversar com os atletas/jogadores sobre o estudo em questão, expor a forma de participação e a colaboração de cada um.

Após conversa com os atletas e explicação dos objetivos da pesquisa, distribuímos pessoalmente os questionários para todos os participantes. A coleta de dados foi realizada no mesmo dia, pois com auxílio do coordenador da escolinha, do técnico do time feminino e do organizador do grupo de amigos, conseguimos o nosso objetivo.

Segundo Gil (2012), uma das principais características da pesquisa descritiva está na utilização de técnicas padronizadas de coleta de dados, e nesse tipo de pesquisa evidenciam-se as que têm por objetivo estudar as características de um grupo, levantando opiniões e atitudes de uma população, e descobrir associações entre variáveis. Os dados serão analisados a partir de estatísticas descritivas e apresentadas através de tabelas e gráficos, sendo assim agrupadas a partir das informações coletadas.

\subsection{Critérios de inclusão e exclusão}

Inclusão: só poderiam participar da pesquisa os praticantes da modalidade futsal com faixa etária entre 15 e 35 anos que estivessem frequentando os treinos pelo menos 3 vezes na semana.

Exclusão: não estar presente na hora da pesquisa, não praticar a modalidade pesquisada pelo menos 3 vezes na semana e os que por opção não quisessem participar. 


\subsection{Análise dos dados}

Foi utilizada a ferramenta de informática planilha eletrônica do Excel para análise descritiva dos dados. Os dados foram analisados a partir de estatísticas descritivas e apresentados através de tabelas, sendo agrupados a partir das informações coletadas.

Por questão de ética não iremos citar nomes, além de termos garantido sigilo absoluto aos envolvidos na pesquisa. Acreditamos que esta garantia deixaria os participantes mais à vontade para expressarem seus pensamentos, necessidades, opiniões e sentimentos.

A análise dos dados foi realizada com a intenção de revelar, através das respostas, como esses praticantes do futsal veem suas condições físicas enquanto atletas amadores, quais as principais lesões enfrentadas, se já buscaram alguma ajuda profissional para tentar diminuir os riscos de lesões.

\section{Discussão e Resultados}

Fizeram parte deste estudo 50 atletas amadores, dos quais 10 eram do sexo feminino pertencentes ao time feminino da cidade, enquanto os 40 entrevistados do sexo masculino estavam divididos com 25 atletas da escolhinha de futsal e 15 atletas que compõem um grupo de amigos que treinam do ginásio do município. Os dados revelam que 9\% dos participantes da pesquisa são do sexo feminino e $91 \%$ do sexo masulino, sendo que as mulheres têm três vezes mais possibilidade de sofrer lesões musculoesqueléticas.

Tabela 1 - Distribuição de atletas por faixa etária

\begin{tabular}{|c|c|c|}
\hline FAIXA ETÁRIA & $\mathbf{N}^{\mathbf{0}}$ & PERCENTUAL \\
\hline $\mathbf{1 5}-\mathbf{2 0}$ anos & 26 & $52 \%$ \\
\hline $\mathbf{2 1}-\mathbf{2 5}$ anos & 12 & $24 \%$ \\
\hline $\mathbf{2 6}-\mathbf{3 0}$ anos & 08 & $16 \%$ \\
\hline $\mathbf{3 1}-\mathbf{3 5}$ anos & 04 & $8 \%$ \\
\hline TOTAL & $\mathbf{5 0}$ & $\mathbf{1 0 0 \%}$ \\
\hline
\end{tabular}

Fonte: Elaboração própria a partir da pesquisa

Os dados nos demonstram que a faixa etária entre 15 e 20 anos é a que mais possui atletas praticantes da modalidade futsal, exatamente $52 \%$, devido ao grande número de jovens que dedicam-se aos esportes em horários de folga e também ao condicionamento físico que a juventude lhes proporciona. Outro fator que pode talvez também contribuir para esse percentual ser elevado foi a pesquisa realizada na escolinha de futsal que desenvolve um trabalho nas categorias de base dessa modalidade esportiva. Com o menor percentual, de $8 \%$, apareceu a faixa etária de 31 a 35 anos.

Entendemos que, quando os praticantes de algum esporte já começam a ultrapassar os 30 anos, o seu corpo começa a sentir os efeitos dos esforços físicos realizados por décadas, ainda mais no futsal, que é conhecido por exigir garra, vigor físico e determinação de seus 
praticantes. Por isso, atletas que já sofreram algum tipo de lesão preferem não colocar mais em risco sua saúde ou treinam com menos frequência. Existe também a questão de os atletas amadores terem que dividir suas atividades físicas com as atividades do trabalho, restando-lhes somente o período noturno para a realização de tais práticas, o que acaba não ocorrendo, pois, quando não é o cansaço, é o pouco tempo que têm disponível para a família.

Sobre as posições em que atuam no futsal, $40 \%$ informaram que jogam como ala direito ou esquerdo; $30 \%$ disseram que atuam como fixo, posição esta que requer muito vigor físico e um bom desempenho de marcação; $20 \%$ relataram que atuam em umas das posições mais perigosas do esporte, que é a de goleiro; e, compondo os $10 \%$ restantes, estão os atletas que jogam na posição de pivô, aqueles atletas mais pesados, com maior estatura e, portanto, os mais lentos.

Em relação à incidência de lesões entre os praticantes do futsal, no estudo verificou-se que, dos cinquenta entrevistados, 38 atletas (76\%) sofreram algum tipo de lesão relacionada com a prática do futsal e apenas 12 (24\%) nunca sofreram nenhum tipo de lesão com esse esporte.

Segundo Prati (2004), as lesões esportivas são provocadas por métodos inadequados de treinamentos, por algum tipo de alteração estrutural que sobrecarregam com mais intensidade determinadas partes do corpo do que outras. Essa questão se dá por problemas como fraqueza muscular, tendinosa ou de ligamentos.

Tabela 2 - Percentual de lesões por posições do Futsal

\begin{tabular}{|c|c|c|c|}
\hline POSIÇÕES & $\mathbf{N}^{\mathbf{0}}$ PESQUISADO & SOFRERAM LESÕES & PERCENTUAL \\
\hline Alas & 17 & 15 & $40 \%$ \\
\hline Fixos & 15 & 10 & $26 \%$ \\
\hline Pivôs & 08 & 08 & $21 \%$ \\
\hline Goleiros & 10 & 05 & $13 \%$ \\
\hline TOTAL & $\mathbf{5 0}$ & $\mathbf{3 8}$ & $\mathbf{1 0 0 \%}$ \\
\hline
\end{tabular}

Fonte: Elaboração própria a partir da pesquisa

Em se tratando da posição em que jogam, observou-se que os jogadores que atuam na posição de ala (direito ou esquerdo) são os que mais sofrem lesão (40\%). Isso por estar relacionado ao fato de que essa posição em quadra é a que mais exige preparo físico dos atletas, pois em ambos os lados da quadra esses jogadores devem impor um rítmo muito intenso com constantes subidas de apoio ao ataque para ajudar os companheiros nos fundamentos de finalização, como também retornar para a defesa a fim de recomposição do sistema defensivo, auxiliando a equipe na marcação.

Em segundo vem a posição do fixo (26\%). São jogadores que devem apresentar como características básicas a marcação e boa leitura de jogo para realizar a antecipação de jogadas, desenvolvendo, assim, muito rapidamente, arrancadas e paradas brucas, o que pode 
comprometer e sobrecarregar algumas regiões musculares, sem falar no constante atrito físico com seus adversários, pois sua função é impedir que a equipe contrária marque gols.

Logo em seguida vêm os jogadores atuantes na posição de pivô (21\%). Estes estão em constante contato físico com o marcador adversário, no caso, o fixo da outra equipe, pois, além de serem os jogadores mais marcados em quadras, geralmente são os mais altos e fortes, características estas que os tornam muito visados pelos opositores para evitar que progridam de forma ofensiva para finalização em gol.

Os goleiros são aqueles que menos sofrem com lesões (13\%), pelo fato de terem pouca locomoção dentro da partida de futsal, mas não significa que estão imunes aos riscos. Como aqui já relatado, as lesões ocorrem com mais frequência nos membros inferiores. Já com os goleiros, eles também costumam apresentar lesões nos membros superiores, principalmente nos dedos, pulso, ombro e cotovelo. Sem falar nas constantes quedas em superfícies duras e no impacto das bolas pesadas na caixa torácica, o que, com o passar dos anos, pode ocasionar algum tipo de problema de saúde no futuro.

De fato, o que se pode observar é que em nenhuma das posições os praticantes ou atletas amadores estão livres de lesões, até mesmo os goleiros, que não se locomovem muito durante uma partida, embora suas lesões aconteçam em outras regiões do corpo, não muito comuns para as demais posições. Apresentam implicações nos membros superiores - mais comuns nos dedos, seguida de ombros, cotovelos e pulsos.

Ribeiro e Costa (2006) afirmam que diversos estudos definem o termo lesão esportiva de diferentes formas, porém a definição mais precisa provém do NAIRS ${ }^{1}$, definindo como lesão esportiva todo acontecimento que limita a participação do atleta por pelo menos um dia após a ocorrência. Na maioria das vezes essa lesão é resultante da ultrapassagem do limite fisiológico, determinando o afastamento, por períodos variados, dos treinos e das competições, para tratamento.

Outros fatores que podem estar relacionados ao surgimento de lesões estão ligados ao preparo físico, aquecimento e alongamentos mal feitos, à posição do jogador, local do treino ou do jogo, tipos de calçados, pancadas ocorridas no decorrer do jogo, fatores psicológicos, treinamentos inadequados, sobrecarga de trabalho e descanso insuficiente.

Tabela 3 - Localização anatômica da lesão

\begin{tabular}{|c|c|c|}
\hline PARTE ANATÔMICA & SOFRERAM LESÕES & PERCENTUAL \\
\hline Tornozelo & 11 & $22 \%$ \\
\hline Joelho & 09 & $18 \%$ \\
\hline Coxa & 06 & $12 \%$ \\
\hline Panturrilha & 06 & $12 \%$ \\
\hline Pé & 05 & $10 \%$ \\
\hline Cotovelo & 04 & $8 \%$ \\
\hline
\end{tabular}

${ }^{1}$ NAIRS - Sistema de Registro Nacional de Lesões dos Estados Unidos 


\begin{tabular}{|c|c|c|}
\hline PARTE ANATÔMICA & SOFRERAM LESÕES & PERCENTUAL \\
\hline Mão & 03 & $6 \%$ \\
\hline Ombro & 03 & $6 \%$ \\
\hline Punho & 02 & $4 \%$ \\
\hline Coluna & 01 & $2 \%$ \\
\hline TOTAL & $\mathbf{3 8}$ & $\mathbf{1 0 0 \%}$ \\
\hline
\end{tabular}

Fonte: Elaboração própria a partir da pesquisa

Em relação à localização anatômica da lesão, nosso estudo constatou que a maioria das lesões acontece realmente nos membros inferiores dos atletas devido à grande intensidade e repetitividade de movimentos a que esses membros são submetidos nos treinos e principalmente nos jogos.

Em relação à localização específica da lesão, apesar dos diversos tipos de lesões citados nos questionários coletados, podemos verificar que a região mais afetada foi o tornozelo $(22 \%)$, pelo fato de ser uma região que fica muito desprotegida na execução de movimentos dos membros inferiores e também por ter que sustentar todo o peso corporal. Logo em seguida vêm as lesões de joelho (18\%). Esta região também apresenta bastante incidência de lesões que tiram os atletas de atividades físicas por longos períodos ou, em certos casos, os praticantes de esportes ficam impossibilitados de jogar por tempo indefinido, tendo que aposentar-se do esporte precocemente. Em se tratando de futebol, esse tipo lesão é a mais comum, chegando a ultrapassar as lesões de tornozelo. Esses dois tipos de lesão articulares (tornozelos e joelhos) dos membros inferiores são as mais comuns devido ao fato da grande sobrecarga que suportam durante uma atividade física, a movimentos repetitivos e, muitas vezes, por estarem ligadas ao péssimo tipo de piso ou calçado que o jogador está utilizando, no futsal principalmente.

Foram citados pelos pesquisados os problemas musculares ocorridos com mais ênfase nas coxas e panturrilhas (ambos 12\%). São grandes grupos musculares que sofrem a sobrecarga da intensidade física e que necessitam de bons aquecimentos e alongamentos antes de colocá-los em esforço. Geralmente isso não acontece com os praticantes de futsal da nossa cidade, dos três grupos observados; apenas o grupo feminino põe esse tipo de benefício em prática.

Uma lesão descrita como uma distensão indica que houve algum grau de ruptura nas fibras musculares, na junção músculo-tendão, no tendão ou na inserção óssea de uma unidade musculotendinosa (COSTA, 2005). De acordo com esse autor, a distensão é provocada por uma força violenta que incide sobre o músculo em atividade, ocorrendo, assim, a ruptura do músculo, da junção ou até do tendão. Isso se dá sempre que essa força ultrapassa a capacidade de resistência ou a flexibilidade da unidade.

Segundo Whiting (2001) apud COSTA (2005), as distensões são classificadas, de acordo com a gravidade, em leves, moderadas e graves. As distensões leves (primeiro grau) não são acompanhadas de ruptura macroscópica, observando-se apenas edema e sensibilidade dolorosa a palpação; na moderada (segundo grau) ocorre certo grau de interrupção da unidade, 
resultando em diminuição de força e mobilidade, contudo sem ruptura completa; na grave (terceiro grau) existe ruptura completa de um ou mais componentes da unidade, estando quase sem mobilidade, com sinal de "gap" e é visivelmente notada (MALONE, 2000 apud WALTRICK, 2004).

Outros locais de lesão também foram apontados pelos praticantes do futsal, como o pé (10\%), cotovelo (8\%), mãos e ombros (6\%), punho (4\%) e coluna (2\%). Conforme os dados da tabela, podemos constatar que quem pratica esportes deve sempre cuidar de sua saúde, realizar consultas médicas periodicamente e realizar acompanhamentos com profissionais qualificados para que esses problemas de saúde não possam afetar o desempenho do corpo no futuro.

Vale destacar que, dos cinquenta entrevistados, 24\% afirmaram que nunca sofreram com problemas de lesões musculoesqueléticas, fatos esses que podem ser explicados pela questão da idade, do sexo, de um bom condicionamento físico ou ainda por consciência pessoal de cada um perante seu corpo. $\mathrm{O}$ atleta amador deve conhecer os limites de seu corpo de modo a não tentar ultrapassar as suas capacidades morfofuncionais.

Sempre que surgirem sinais de alarme, sinalizadores de uma eventual lesão, a suspensão imediata da atividade deverá ser a norma, bem como a avaliação por um especialista qualificado.

Foi questionado aos praticantes do futsal sobre em qual o momento eles se lesionaram, dando como alternativas de respostas o jogo, treino físico ou coletivo. Diante das respostas fornecidas, o jogo (42\%) foi o momento em que os atletas amadores mais sofreram suas lesões. É nesse momento em que os competidores colocam à prova tudo que foi treinado no decorrer da semana ou até de meses, onde, no calor da emoção e incentivados pela torcida, os jogadores ultrapassam seus limites, podendo afetar sua saúde.

Já 32\% informaram que as lesões que sofreram foi durante a realização dos treinos. Esta etapa é considerada de preparação tanto do físico como do psicológico. Os maiores problemas estão na execução errada dos movimentos ou até mesmo na falta de orientação por pessoas preparadas, somando-se o fato de que muitos desses jogadores amadores não têm o hábito de realizar alongamentos nem aquecimentos antes da prática dos exercícios físicos.

Completando o percentual do momento em que esses atletas mais sofreram lesões, houve os que disseram que suas lesões ocorrem durante os coletivos (26\%). Este momento já é mais de relaxar, pois geralmente é executado nos finais dos treinamentos físicos, onde os corpos já estão bastante desgastados, ou, então, em vésperas de jogos, só para soltar um pouco a musculatura, não exigindo tanta intensidade como nos treinos ou nos jogos.

Questionou-se também que tipo de movimento o atleta estava realizando no momento em que sofreu a lesão. Foi um questionamento aberto para que os praticantes da modalidade do

\footnotetext{
${ }^{2}$ GAP - significa lacuna, vão ou brecha.
} 
futsal fornecessem as informações verdadeiras, pois em uma questão fechada eles estariam fixados somente aos itens impostos.

Tabela 4 - Movimento realizado no momento da lesão

\begin{tabular}{|c|c|c|}
\hline ATIVIDADES & SOFRERAM LESÕES & PERCENTUAL \\
\hline Chute & 08 & $21 \%$ \\
\hline Corrida & 07 & $18 \%$ \\
\hline Disputa de bola & 06 & $16 \%$ \\
\hline Salto & 05 & $13 \%$ \\
\hline Giro & 05 & $13 \%$ \\
\hline Passe & 04 & $11 \%$ \\
\hline Arremesso & 03 & $8 \%$ \\
\hline TOTAL & $\mathbf{3 8}$ & $\mathbf{1 0 0 \%}$ \\
\hline
\end{tabular}

Fonte: Elaboração própria a partir da pesquisa

De acordo com os dados coletados, optamos por expor as respostas dos entrevistados na forma de tabela, pois assim facilitariam a visualização e o entendimento. Conforme a tabela, os atletas se lecionaram mais nos momentos dos chutes (21\%), aquela situação onde ocorre a explosão da musculatura para transferir a potência para a execução do movimento. Também foi bastante citado o momento da corrida (18\%), ocorrendo sempre nos momentos de arrancada ou parada. A disputa de bola (16\%) foi bastante mencionada. Este é o momento onde há muito contato físico entre os atletas, produzindo exagerado uso da força nas jogadas ou provocando a queda do adversário. Os saltos e os giros (13\%) não deixaram de ser mencionados pelos pesquisados, principalmente por parte dos goleiros e dos pivôs. Os primeiros por causa dos saltos que executam; os segundos, devido ao giro que realizam em cima dos marcadores, forçando assim as articulações dos joelhos. Logo em seguinda citaram os passes (11\%). Este fundamento deve ser bem executado por todos os jogadores, independente de posição que atuam em quadra. Por isso, quando realizado com um mais força, pode provocar uma lesão muscular. Por fim foi citado, com menos ênfase, o arremesso (8\%), mas lembrado por parte dos goleiros, que devido aos movimentos repetitvos, ocasiona sérias lesões nos ombros.

No último questionamento, também aberto, foi perguntando se eles sabiam por quais fatores as lesões ocorriam. Por surgirem muitas respostas parecidas, resolvemos selecionar algumas para montarmos o objetivo desse questionamento.

Muitos dos entrevistados têm consciência de que as lesões ocorrem por culpa deles próprios, pois quando uma pessoa sustenta um corpo saudável, segue as orientações de profisionais qualificados, proporciona descanço para o corpo repor as energias, disponibiliza tempo para recuperação quando sente logo o sinal de alerta, a tendência é sempre dispor de uma saúde de ferro. Mas ainda houve aqueles que não apontaram como sendo do jogador a responsabilidade por problemas que acontecem em decorrência, por exemplo, do tipo de superfície onde são realizados os treinos ou os jogos. Obtivemos questionamentos fora destas 
duas problemáticas acima, como os que acontecem em decorrência da idade, do sexo (o corpo feminino é mais frágil), pelo excesso de confiança etc.

Assim, é importante que o atleta esteja sempre com suas qualidades físicas adequadas, no intuito de diminuir as possibilidades de algum trauma bem como de permitir uma recuperação mais rápida da lesão sofrida.

\section{Considerações Finais}

O futsal é um esporte que exige muito esforço físico do atleta. Desta forma é possível perceber que esses atletas são bastante acometidos por lesões musculoesqueléticas, Essas lesões acabam afetando as estruturas físicas e musculares desses atletas amadores.

Acredita-se que os atletas são submetidos a treinamentos inadequados, a uma carga excessiva de treinamentos, ao pouco tempo de recuperação para o corpo, à uma alimentação incorreta ou ainda ao hábito de não realizar de aquecimentos ou alongamentos, gerando assim maiores probabilidades de sofrerem lesões em treinos e competições.

Constatamos que as lesões que mais ocorrem nos atletas amadores praticantes de futsal na cidade de Morro do Chapéu do Piauí são as lesões nos membros inferiores, como das articulações dos tornozelos e joelhos e as musculares das coxas e panturrilhas.

Foi possível também observar que a posição que mais sofre com problemas de lesões é a dos alas. Isso está relacionado ao fato de que esta posição em quadra é a que mais exige preparo físico dos atletas, pois em ambos dos lados da quadra esses jogadores devem impor um ritmo muito intenso com constantes subidas de apoio ao ataque para ajudar os companheiros nos fundamentos de finalização, como também retornar para a defesa a fim de recomposição do sistema defensivo, auxiliando a equipe na marcação.

Constatou-se que as lesões ocorrem com mais incidência durante a realização dos jogos, pois é nesse momento em que os atletas amadores mais sofrem suas lesões; é nesse momento que os competidores colocam à prova tudo que foi treinado no decorrer da semana ou até de meses; é nesse momento em que, no calor da emoção, incentivados pela torcida, os jogadores ultrapassam seus limites, podendo afetar sua saúde.

Outro fator importante foi que os entrevistados relataram que sofreram suas lesões durante os fundamentos dos chutes, aquela situação onde ocorre a explosão da musculatura para transferir a potência para a execução do movimento. Muitos dos atletas amadores que já sofreram algum tipo de lesão têm consciência de que foi por culpa deles próprios.

Com este estudo, clonclui-se que os praticantes do futsal podem ser prejudicados por vários tipos de lesão, mas que as musculoesqueléticas têm uma incidência maior sobre os atletas amadores. Os resultados deste estudo nos trouxeram um olhar mais amplo sobre o tema. Deste modo, servirá como fonte para futuras pesquisas. Assim, é importante que o atleta esteja sempre 
com suas qualidades físicas adequadas, no intuito de diminuir as possibilidades de algum trauma, bem como de permitir uma recuperação mais rápida da lesão sofrida.

\section{Referências}

ANDREWS, J. R.; HARRELSON, G. L.; WILK, K. E. Reabilitação física das lesões desportivas. 2. ed. Rio de Janeiro: Guanabara Koogan, 2000.

CONFEDERAÇÃO BRASILEIRA DE FUTSAL. Disponível em: http://www.cbfs.com.br. Acesso em: Set. 2017.

COHEN, M.; ABDALLA, R. J. Lesões nos esportes: diagnóstico, prevenção, tratamento. Rio de Janeiro: Revinter, 2005.

DANTAS, E. H. M. A prática da preparação física. Rio de Janeiro: Shape, 1998.

FERNANDEZ, R. O esporte e o desenvolvimento no futsal. 2014. Disponível em <http://www.fustalbrasil.com.br/artigos/artigos> Acesso em: Ago. 2017.

GAETHER, G. Psicologia somática aplicada ao esporte de alto rendimento. (Dissertação de mestrado, Universidade Federal de Santa Catarina). Florianópolis, 2012.

GIL, Antonio Carlos. Como elaborar projetos de pesquisa. 4. ed. São Paulo: Atlas, 2012.

NETO, C. S. P. Lesões intervenientes nas posições táticas no futsal. Disponível em:. Acesso em: 07 ago. 2017.

PRATI, F. A. M. Lesão: fatores desencadeantes e prevenção. Revista Fisioterapia em Movimento, v. V, n.1, p.9-20, abr/set. 2004.

RIBEIRO, R.N.; COSTA, L.O.P. Análise epidemiológica de lesões no futebol de salão durante o XV campeonato Brasileiro de seleções sub-20. Rev. Bras. Med. Esporte. 2006.

SANTOS, F. J. et al. Prevalência de lesões de membros inferiores em atletas de futsal feminino. Disponível em: <http://www.revista.universo.edu.br/index.php> Acesso em: 23 ago.2017.

SANDOVAL, A.E.P. Medicina do esporte: princípios e prática. Porto Alegre: Artmed, 2005. SOARES, H.;

WALTRICK, R. D. Incidência de lesão em equipes de futsal. Monografia apresentada ao curso de fisioterapia. Universidade do Sul de Santa Catarina, Tubarão, 2004.

WHITING, W. C. Biomecânica da lesão musculoesquelética. Rio de Janeiro: Guanabara Koogan, 2001.

Artigo recebido em: 08/11/2017

Artigo aceito para publicação em: 05/12/2017 